\title{
Affective Factors That Contribute to the Quality of Life of Juvenile Inmates with Attention-Deficit/Hyperactivity Disorder: A Focus on Items from the Korean Youth Self Report
}

\author{
Hyesoon Kim and Bongseog Kim \\ Department of Psychiatry, Sanggye Paik Hospital, Inje University College of Medicine, Seoul, Korea
}

Objectives: This study investigated quality of life in Korean juvenile inmates with attention-deficit/hyperactivity disorder (ADHD) and the impact of behavioral and emotional problems on quality of life.

Methods: In total, 200 inmates were evaluated using the Korean version of the Mini-International Neuropsychiatric Interview (KMINI) and the Korean version of the Kiddie-Schedule for Affective Disorders and Schizophrenia-Present and Lifetime (K-SADS-PL-K). We extracted the inmates with ADHD and evaluated their quality of life, behavioral problems, and emotional problems with the Pediatric Quality of Life Inventory (PedsQL) and the Korean Youth Self Report (K-YSR) scale. Descriptive statistics, Pearson correlation analysis, and multiple regression analysis were conducted.

Results: Among the 200 total inmates, 68 were diagnosed with ADHD by the K-SADS-PL-K. Most of the correlations between PedsQL scores and K-YSR items were significant. Multiple regression analysis showed that PedsQL could be predicted by affective problems (among the DSM-oriented scales of the K-YSR) and attention problems (among the syndrome scales of the K-YSR).

Conclusion: Our results demonstrate that, among juvenile inmates with ADHD, quality of life was negatively correlated with most behavioral and emotional problems. Meanwhile, the significant influence of affective and attention problems on inmates' quality of life suggests the necessity of comprehensive treatments for this group.

Key Words: Quality of life; Attention deficit-hyperactivity disorder; Behavioral problem; Affective symptoms.

Received: June 12, 2019 / Revision: July 13, 2019 / Accepted: July 17, 2019

Address for correspondence: Bongseog Kim, Department of Psychiatry, Sanggye Paik Hospital, Inje University College of Medicine, 1342 Dongil-ro, Nowon-gu, Seoul 01757, Korea

Tel: +82-2-950-1087, Fax: +82-2-936-8069, E-mail: kimbs328@paik.ac.kr

\section{INTRODUCTION}

In recent years, media reports of juvenile crime have increased in Korea. Juvenile crime itself is not a newly emerging social problem, but it raises questions about the effectiveness of the social system and issues such as a lack of interest in juvenile crime and juvenile law. According to a 2014 study on the actual conditions and characteristics of violent juvenile crimes, the percentage of juvenile offenders increased after 2007, and the proportion of violent crime offenders among juvenile offenders was higher than that among adult offenders [1]. In response to the seriousness of juvenile crime and the everyounger age of juvenile offenders, it is necessary to revise the current system of corrective measures, including measures

This is an Open Access article distributed under the terms of the Creative Commons Attribution Non-Commercial License (https://creativecommons.org/licenses/by-nc/4.0) which permits unrestricted non-commercial use, distribution, and reproduction in any medium, provided the original work is properly cited. taken towards juvenile inmates and the use of accurate evaluation tools.

In particular, psychological and medical factors including male sex [2], impaired cognitive ability [3], and childhood abuse [4] have been identified as risk factors in juvenile inmates. A high proportion (40-90\%) of juvenile detainees have one or more psychiatric disorders [5-11], and attention-deficit/hyperactivity disorder (ADHD) has attracted particular attention in this context. In several studies conducted in North America, Finland, Sweden, and Canada, a high prevalence of adolescent ADHD was found (in $71 \%$ of male inmates), and $45 \%$ reported persistent symptoms [12]. In addition, a 2009 study of the Scottish Detention Center by Young et al. [13] suggested that ADHD may be a greater contributor to disruptive behavior than antisocial personality disorder.

It is increasingly likely that ADHD symptoms during adolescence or adulthood are a contributing factor or predictor 
of crime. At the same time, the prognosis of individuals with ADHD should be approached not only from the perspective of symptom treatment, but also with a focus on quality of life. Quality of life is a subjective concept that cannot be defined by a single aspect; however, it is distinct from the severity of the symptoms or the progression of the disease. The concept of quality of life emphasizes general well-being and everyday functioning in various areas of an individual's life, and is not limited to the direct effects of the severity of ADHD symptoms [14]. Nonetheless, the severity of symptoms in ADHD patients may also affect their quality of life by impacting their daily functions and their interactions and relationships with family members [15]. Although there have been many studies on the effects of emotional states on the quality of life of adolescents with ADHD in Korea [16], few studies have studied juvenile inmates with ADHD, especially with a focus on their quality of life.

Therefore, in this study, the quality of life, emotions, and problem behaviors of male juvenile inmates were evaluated and analyzed with the goal of identifying mutual correlations and patterns of influence.

\section{METHODS}

\section{Subjects}

This study was conducted from December 2015 to January 2016 among 200 juvenile inmates. We selected 68 patients diagnosed with ADHD through an evaluation using the Korean version of the Kiddie-Schedule for Affective Disorders and Schizophrenia-Present and Lifetime (K-SADS-PL). Participants were provided with detailed instructions and guidance on the purpose and process of the study. Self-signed consent forms and self-report questionnaires were submitted, and for juvenile inmates under the age of 18 , additional consent was provided by their parent or guardian. This study was approved by the Clinical Research Ethics Committee of Sanggye Paik Hospital (IRB No. SGPAIK-2015-06-022-002).

\section{Procedure}

All participants completed self-report questionnaires, and mental health practitioners and clinical psychologists conducted structured diagnostic interviews to gather information on participants' demographic characteristics and psychiatric diagnoses and evaluations.

\section{Scales}

Korean version of the Kiddie-Schedule for Affective Disorders and Schizophrenia-Present and Lifetime

The K-SADS-PL comprises semi-structured interviews for psychiatric diagnoses. The reliability and validity of its Korean version (K-SADS-PL-K) were demonstrated by Kim et al. [17] for the diagnosis of major diseases of children and adolescents including ADHD, oppositional defiant disorder, and tic disorder. In this study, we utilized the K-SADS-PL-K to screen for ADHD and to confirm diagnoses of oppositional defiant disorder, conduct disorder, and tic disorder.

\section{Korean version of the Mini-International Neuropsychiatric Interview 5.0}

The Mini-International Neuropsychiatric Interview (MINI) 5.0 is a structured interview for psychiatric diagnoses following the DSM-IV and ICD-10 criteria [18]. According to Yoo et al. [19], the Korean version (K-MINI) showed kappa values ranging from 0.22 to 0.93 in the diagnosis of conditions contained in the Korean version of the DSM-IV, with good overall validity. In this study, we used the K-MINI 5.0 to identify comorbid diseases, such as mood disorders, in juveniles.

\section{Korean version of the Pediatric Quality of Life Inventory} 4.0 Generic Core Scales

We used the Korean version of the Pediatric Quality of Life Inventory 4.0 Generic Core Scales (PedsQL 4.0) for evaluating patients' quality of life. The PedsQL 4.0 is a tool used to measure the difficulties of patients or caregivers in four areas: physical functioning, emotional functioning, social functioning, and school functioning [20]. The Korean version has also been proven to have good model fit and discriminant validity [21].

\section{Korean Youth Self Report}

The Korean Youth Self Report (K-YSR) youth self-assessment scale is based on the Youth Self Report (YSR) of Achenbach and Rescorla [22], with its second standardization carried out by Oh et al. [23] in 2011. Its test reliability was good, and discriminant validity and concurrent validity were verified [24]. The K-YSR is an evaluation tool that can be used to screen for problem behaviors and clinical diagnoses. This study used the K-YSR to evaluate the emotional and behavioral problems of juvenile inmates with ADHD.

\section{Statistical analysis}

Each item of the PedsQL 4.0 and K-YSR among the 68 juvenile inmates with $\mathrm{ADHD}$ and the 132 other juvenile inmates was analyzed using descriptive statistics and the t-test. Pearson correlation analysis was performed between the two scales. In addition, multiple regression analysis was conducted to examine the impact of the subscales of the K-YSR on quality of life. Statistical analysis was performed using SPSS version 25 (IBM Corp., Armonk, NY, USA). p-values $<0.05$ were con- 
sidered to indicate statistical significance.

\section{RESULTS}

Mean age and prevalence of psychiatric disorders in all 200 juvenile inmates and in the subgroup diagnosed with ADHD

The mean age of the 200 juvenile inmates was $18.91 \pm 1.61$ years, and the prevalence of psychiatric disorders was $92.5 \%$ $(\mathrm{n}=185)$. Conduct disorder was the most prevalent $(\mathrm{n}=110$; $55 \%)$, followed by bipolar disorder ( $\mathrm{n}=95 ; 47.5 \%)$, and oppositional defiant disorder $(\mathrm{n}=87 ; 43.5 \%)$ (Table 1$)$.

The mean age of the 68 juvenile inmates diagnosed with

Table 1. Demographic characteristics

\begin{tabular}{lcc}
\hline & $\begin{array}{c}\text { Total group } \\
(\mathrm{n}=200)\end{array}$ & $\begin{array}{c}\text { ADHD } \\
\text { subgroup } \\
(\mathrm{n}=68)\end{array}$ \\
\hline $\begin{array}{l}\text { Gender } \\
\text { Male }\end{array}$ & $200(100)$ & $68(100)$ \\
Age (yr) & $18.91 \pm 1.61$ & $18.63 \pm 1.55$ \\
Comorbidities & & \\
Total & $185(92.5)$ & $64(94.1)$ \\
Major depressive disorder & $33(16.5)$ & $19(27.9)$ \\
Bipolar disorder & $95(47.5)$ & $41(60.3)$ \\
Oppositional defiant disorder & $87(43.5)$ & $45(66.2)$ \\
Conduct disorder & $110(55.0)$ & $44(64.7)$ \\
Tic disorder & $59(29.5)$ & $27(39.7)$ \\
ADHD & $68(34.0)$ & $68(100)$
\end{tabular}

Variables are presented as meantstandard deviation or $\mathrm{n}(\%)$. ADHD: attention-deficit/hyperactivity disorder
ADHD using the K-SADS-PL was $18.63 \pm 1.55$ years. Among them, 64 (94.1\%) had one or more other psychiatric disorders besides ADHD. Common comorbidities included oppositional defiant disorder ( $\mathrm{n}=45 ; 66.2 \%$ inmates), conduct disorder $(n=44 ; 64.7 \%)$ and bipolar disorder $(n=41 ; 60.3 \%)$. In addition, the prevalence of all disorders in the ADHD subgroup was higher than in the entire group (Fig. 1).

\section{Comparisons of quality of life and other problems ac- cording to the diagnosis of ADHD}

When the PedsQL and K-YSR scores were compared according to the diagnosis of ADHD, the quality of life was lower in the ADHD subgroup for the total score and for all items (Table 2). The ADHD subgroup showed high scores for all items dealing with problem behavior. The results of the t-test showed that there was a significant difference in all items, except social functioning in the PedsQL.

\section{Correlations between quality of life and problem be- haviors in participants with ADHD}

Correlations between quality of life in juvenile inmates with $\mathrm{ADHD}$ and their emotional and behavioral problems were evaluated (Table 3). Most of the K-YSR subscales showed significant relationships with quality of life, except for somatic problems. The PedsQL score and all four subitems showed significant correlations with emotional factors (syndrome scales: anxious/depressed, withdrawn/depressed; broad band scales: internalizing; DSM-oriented scales: affective problems, anxiety problems) and aggression-related factors (syndrome scales: aggressive behavior; broad band scales: externalizing;

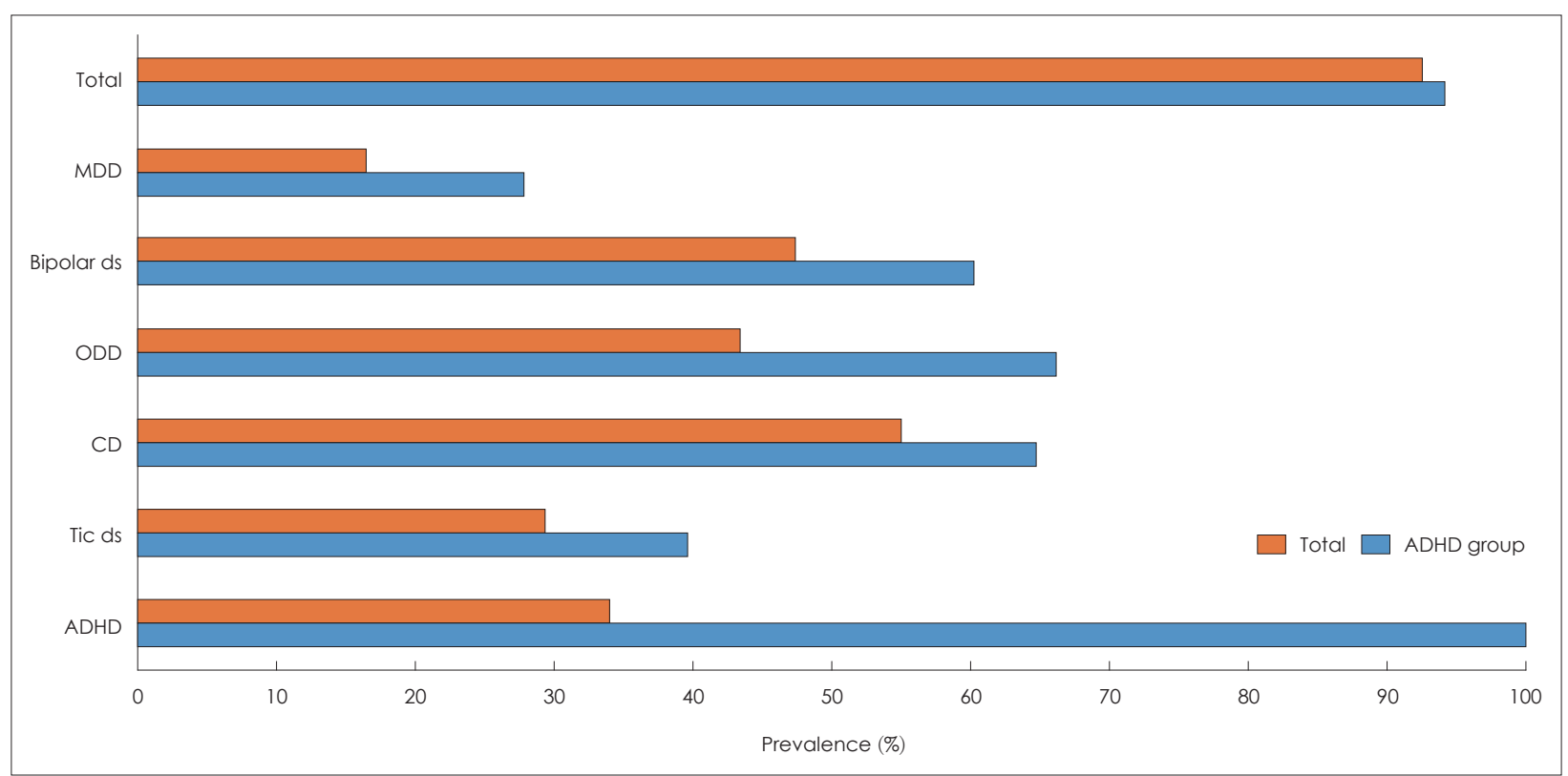

Fig. 1. Prevalence of comorbid diseases. MDD: major depressive disorder, ODD: oppositional defiant disorder, CD: conduct disorder, ADHD: attention-deficit/hyperactivity disorder 
Table 2. Comparisons of PedsQL and K-YSR subscale T-scores between the non-ADHD and ADHD group

\begin{tabular}{|c|c|c|c|c|c|}
\hline \multirow[b]{2}{*}{ Scale } & \multirow[b]{2}{*}{$\begin{array}{l}\text { Total group } \\
\qquad(n=200)\end{array}$} & \multicolumn{4}{|c|}{ Subgroup comparison } \\
\hline & & Non-ADHD $(n=132)$ & ADHD $(n=68)$ & $\begin{array}{c}\text { Mean } \\
\text { differences }\end{array}$ & $\mathrm{p}$ \\
\hline PedsQL total & $80.54 \pm 16.55$ & $83.84 \pm 14.86$ & $74.15 \pm 17.87$ & 9.68 & $0.000 *$ \\
\hline PedsQL somatic & $87.53 \pm 15.79$ & $89.35 \pm 14.70$ & $84.01 \pm 17.31$ & 5.34 & $0.032^{\dagger}$ \\
\hline PedsQL emotional & $71.80 \pm 24.66$ & $76.60 \pm 21.64$ & $62.28 \pm 27.42$ & 14.43 & $0.000^{*}$ \\
\hline PedsQL social & $88.90 \pm 17.10$ & $90.72 \pm 14.83$ & $85.37 \pm 20.47$ & 5.35 & 0.058 \\
\hline PedsQL school & $69.75 \pm 26.62$ & $75.27 \pm 24.31$ & $59.04 \pm 27.80$ & 16.22 & $0.000^{*}$ \\
\hline \multicolumn{6}{|l|}{ K-YSR subscale (T score) } \\
\hline \multicolumn{6}{|l|}{ Syndrome scales } \\
\hline Anxious/Depressed & $54.85 \pm 7.28$ & $53.41 \pm 6.09$ & $57.62 \pm 8.54$ & -4.21 & $0.000^{*}$ \\
\hline Withdrawn/Depressed & $55.17 \pm 7.12$ & $54.40 \pm 6.84$ & $56.63 \pm 7.45$ & -2.23 & $0.036^{\dagger}$ \\
\hline Somatic complaints & $55.02 \pm 7.26$ & $54.11 \pm 6.90$ & $56.75 \pm 7.67$ & -2.64 & $0.015^{*}$ \\
\hline Social problems & $55.06 \pm 7.35$ & $53.92 \pm 6.63$ & $57.25 \pm 8.18$ & -3.33 & $0.004^{*}$ \\
\hline Thought problems & $55.37 \pm 7.30$ & $54.00 \pm 6.43$ & $58.00 \pm 8.14$ & -4.00 & $0.001 *$ \\
\hline Attention problems & $55.34 \pm 8.43$ & $53.63 \pm 6.98$ & $58.63 \pm 9.94$ & -5.01 & $0.000^{*}$ \\
\hline Rule-breaking behavior & $67.19 \pm 8.51$ & $65.78 \pm 8.09$ & $69.91 \pm 8.70$ & -4.13 & $0.001^{*}$ \\
\hline Aggressive behavior & $57.82 \pm 9.74$ & $55.82 \pm 8.15$ & $61.68 \pm 11.32$ & -5.85 & $0.000^{*}$ \\
\hline \multicolumn{6}{|l|}{ Broad band scales } \\
\hline Internalizing & $50.12 \pm 13.39$ & $47.72 \pm 12.83$ & $54.74 \pm 13.34$ & -7.02 & $0.000^{*}$ \\
\hline Externalizing & $61.75 \pm 14.69$ & $58.93 \pm 13.65$ & $67.18 \pm 15.20$ & -8.25 & $0.000 *$ \\
\hline Total & $54.77 \pm 14.47$ & $51.71 \pm 13.18$ & $60.68 \pm 15.09$ & -8.97 & $0.000^{*}$ \\
\hline \multicolumn{6}{|l|}{ DSM-oriented scales } \\
\hline Affective problems & $56.32 \pm 8.69$ & $54.98 \pm 7.74$ & $58.90 \pm 9.83$ & -3.91 & $0.005^{*}$ \\
\hline Anxiety problems & $54.88 \pm 7.87$ & $53.47 \pm 6.77$ & $57.60 \pm 9.10$ & -4.13 & $0.001^{*}$ \\
\hline Somatic problems & $54.65 \pm 7.19$ & $53.73 \pm 6.75$ & $56.41 \pm 7.71$ & -2.68 & $0.017^{\dagger}$ \\
\hline ADH problems & $55.72 \pm 8.78$ & $53.60 \pm 7.15$ & $59.82 \pm 10.14$ & -6.23 & $0.000^{*}$ \\
\hline Oppositional problems & $57.50 \pm 9.90$ & $55.60 \pm 7.78$ & $61.19 \pm 12.30$ & -5.60 & $0.001^{*}$ \\
\hline Conduct problems & $62.85 \pm 10.03$ & $60.75 \pm 9.54$ & $66.90 \pm 9.75$ & -6.15 & $0.000^{*}$ \\
\hline
\end{tabular}

Variables are presented as mean \pm standard deviation. ${ }^{*} p<0.01,{ }^{\dagger} p<0.05$. ADHD: attention-deficit/hyperactivity disorder, DSM: Diagnostic and Statistical Manual of Mental Disorders, K-YSR: Korean Youth Self Report, PedsQL: Pediatric Quality of Life Inventory version 4.0 Generic Core Scale

DSM-oriented scales: conduct problems). The following other significant correlations were found.

The PedsQL total score and emotional factors showed a significant correlation with all items, except DSM-oriented somatic problems.

The physical factors of the PedsQL showed significant correlations with all items except thought problems and rulebreaking behavior among the syndrome scales and somatic problems among the DSM-oriented scales.

The social factors of the PedsQL showed significant correlations with all items except attention problems and rulebreaking behavior among the syndrome scales and somatic problems among the DSM-oriented scales.

The PedsQL factor dealing with school functioning was significantly correlated with all items except somatic complaints among the syndrome scales and somatic problems among the DSM-oriented scales.

\section{Problem behavior factors affecting the quality of life of juvenile inmates with ADHD}

After confirming the correlation between quality of life and each problem behavior factor, multiple regression analysis was conducted to quantify the influence of these variables on quality of life (Table 4). The PedsQL total score was used as a dependent variable and each subitem of the K-YSR was used as an independent variable. DSM-oriented affective problems and attention problems among the syndrome scales were found to have the most significant effect on the total score of quality of life evaluated using the PedsQL.

In model 2, which was finally chosen by the stepwise selection method, the explanatory power of the DSM-oriented affective scale item had the highest predictive power, with $44.4 \%$. The attention problems among the syndrome scales had an additional predictive power of $4.3 \%$. Both of these findings were significant ( $\mathrm{p}=0.000 ; \mathrm{p}=0.013$, respectively). 
Table 3. Correlation of PedsQL and K-YSR subscales (ADHD group, $n=68$ )

\begin{tabular}{|c|c|c|c|c|c|}
\hline & PedsQL total & PedsQL somatic & PedsQL emotional & PedsQL social & PedsQL school \\
\hline \multicolumn{6}{|l|}{ K-YSR subscale (T score) } \\
\hline \multicolumn{6}{|l|}{ Syndrome scales } \\
\hline Anxious/depressed & $-0.633^{*}$ & $-0.409 *$ & $-0.604^{*}$ & $-0.542^{*}$ & $-0.469 *$ \\
\hline Withdrawn/depressed & $-0.547^{*}$ & $-0.446^{*}$ & $-0.492^{*}$ & $-0.347^{*}$ & $-0.432 *$ \\
\hline Somatic complaints & $-0.324^{*}$ & $-0.244^{\dagger}$ & $-0.324^{*}$ & $-0.244^{\dagger}$ & -0.217 \\
\hline Social problems & $-0.586^{*}$ & $-0.413^{*}$ & $-0.500 *$ & $-0.512^{*}$ & $-0.452^{*}$ \\
\hline Thought problems & $-0.497^{*}$ & -0.191 & $-0.547^{*}$ & $-0.480^{*}$ & $-0.387^{*}$ \\
\hline Attention problems & $-0.590 *$ & $-0.460^{*}$ & $-0.527^{*}$ & -0.236 & $-0.592^{*}$ \\
\hline Rule-breaking behavior & $-0.405^{*}$ & -0.200 & $-0.402^{*}$ & -0.233 & $-0.431^{*}$ \\
\hline Aggressive behavior & $-0.427^{*}$ & $-0.242^{\dagger}$ & $-0.490 *$ & $-0.261^{\dagger}$ & $-0.346^{*}$ \\
\hline \multicolumn{6}{|l|}{ Broad band scales } \\
\hline Internalizing & $-0.611^{*}$ & $-0.407^{*}$ & $-0.590^{*}$ & $-0.483^{*}$ & $-0.462^{*}$ \\
\hline Externalizing & $-0.459 *$ & $-0.243^{\dagger}$ & $-0.473^{*}$ & $-0.292^{\dagger}$ & $-0.435^{*}$ \\
\hline Total & $-0.623^{*}$ & $-0.371^{*}$ & $-0.606^{*}$ & $-0.437^{*}$ & $-0.555^{*}$ \\
\hline \multicolumn{6}{|l|}{ DSM-oriented scales } \\
\hline Affective problems & $-0.672^{*}$ & $-0.470^{*}$ & $-0.660^{*}$ & $-0.469 *$ & $-0.523^{*}$ \\
\hline Anxiety problems & $-0.492 *$ & $-0.288^{\dagger}$ & $-0.497^{*}$ & $-0.410^{*}$ & $-0.375^{*}$ \\
\hline Somatic problems & -0.129 & -0.148 & -0.154 & -0.104 & -0.004 \\
\hline ADH problems & $-0.546^{*}$ & $-0.415^{*}$ & $-0.473^{*}$ & -0.225 & $-0.570^{*}$ \\
\hline Oppositional problems & $-0.376^{*}$ & $-0.248^{\dagger}$ & $-0.417^{*}$ & -0.192 & $-0.311^{*}$ \\
\hline Conduct problems & $-0.415^{*}$ & $-0.241^{\dagger}$ & $-0.415^{*}$ & $-0.266^{\dagger}$ & $-0.381^{*}$ \\
\hline
\end{tabular}

${ }^{*} p<0.01,{ }^{\dagger} p<0.05$. ADHD: attention-deficit/hyperactivity disorder, K-YSR: Korean Youth Self Report, PedsQL: Pediatric Quality of Life Inventory version 4.0 Generic Core Scale

Table 4. Stepwise multiple linear regression analysis of the relationship of PedsQL total score and K-YSR subscales among ADHD group

\begin{tabular}{lrrrr}
\hline \multicolumn{1}{c}{ Model } & $\beta$-coefficient & \multicolumn{1}{c}{ SE } & \multicolumn{1}{c}{$P$} & Adj R \\
\hline 1 (Constant) & 146.105 & 9.883 & 0.000 & \\
DSM-affective & -1.222 & 0.166 & 0.000 & 0.444 \\
2 (Constant) & 147.308 & 10.459 & 0.000 & \\
DSM-affective & -0.904 & 0.202 & 0.000 & \\
Attention problems & -0.510 & 0.200 & 0.013 & 0.487 \\
\hline
\end{tabular}

ADHD: attention-deficit/hyperactivity disorder, K-YSR: Korean Youth Self Report, PedsQL: Pediatric Quality of Life Inventory version 4.0 Generic Core Scale, SE: standard error

\section{DISCUSSION}

This study assessed the quality of life and emotional and behavioral factors reported by juvenile inmates and confirmed the presence of significant correlations between the factors. It also examined the subjective emotional and behavioral factors that affected juvenile inmates' quality of life. Among the total 200 juvenile inmates, 68 (34\%) with ADHD were identified through the K-SADS-PL-K. Previous studies have reported a widespread prevalence of ADHD in delinquent adolescents, ranging from $4 \%$ to $72 \%$, which is $3-5$ times higher than in controls from the general population $[25,26]$.

Conduct disorder, oppositional defiant disorder, and bipo- lar disorder were the most prevalent diseases among the 200 juvenile inmates included in this study. The same results were obtained for juvenile inmates with ADHD. ADHD is known to occur in $40-60 \%$ of children and adolescents with disruptive disorders such as conduct disorder and oppositional defiant disorder [27]. Conduct disorder and oppositional defiant disorder were found to be present in $64.7 \%$ and $66.2 \%$ of the 68 juvenile inmates with ADHD, respectively, which is at the upper limit of prevalence among general studies of pediatric populations. In addition, $86.8 \%(n=59)$ of the juvenile inmates with ADHD had three or more comorbid diseases, and these individuals should receive urgent interventions. Appropriate treatment should be provided if ADHD is suspected in a juvenile inmates. This is consistent with the difference in the mean scores of the PedsQL and K-YSR scales between the overall sample of 200 juvenile inmates and the subgroup of 68 adolescents with ADHD.

The correlation between quality of life in the subjects with ADHD, analyzed using the PedsQL, and the subscales of the K-YSR showed that the externalization and internalization scale, depression/anxiety scale, inferiority scale, social immaturity scale, thought problems scale, and the aggression scale, as well as the DSM-oriented emotion, anxiety, hostile rebellion, and behavioral disturbance scales correlated with all four subitems and total scores of the PedsQL. This association with 
emotional factors is consistent with previous research [16]. In addition, the results of this study showed that aggressive behavior (among the syndrome scales), externalization (among the broad band scales), and conduct problems (among the DSM-oriented scales) were significantly associated with quality of life in subjects with ADHD. This is related to impaired self-regulation in individuals with ADHD. Previous studies have reported impulsive responses [28], mood instability, and low frustration tolerance [29] among ADHD-related factors. In addition, in a study of adult male inmates in Scotland, prisoners who had ADHD committed violent crimes eight times more often than other prisoners, and the figure was estimated to be six times as high even when controlling for antisocial personality disorder [13]. Taken together, these results suggest that ADHD symptoms may be associated with sudden problems and incidents in ADHD patients' lives. Adolescents with ADHD are especially vulnerable, so the aggravation of ADHD and its symptoms may cause not only deterioration in the quality of life of inmates, but also increased costs and incidents within the facility [30].

Affective problems (among the DSM-oriented scales) were confirmed to be a factor affecting the quality of life of juvenile inmates with $\mathrm{ADHD}$, in accordance with a previous study in which depressive symptoms were observed as a strong predictor of quality of life in adolescents with ADHD. In addition, the results of this study showed that ADHD participants' self-reported attention/concentration problems were an additional predictor. A multidisciplinary approach that focuses on emotional problems and improving attention is needed for the treatment of juvenile inmates with ADHD.

\section{CONCLUSION}

In this study, the prevalence and the number of comorbidities among juvenile inmates with ADHD were observed, and the quality of life, emotional problems, and problem behaviors of the juveniles with ADHD were evaluated. Compared with other juvenile inmates, the overall quality of life of those with ADHD was lower and problems involving emotional and behavioral factors were more common. The quality of life of juvenile inmates with ADHD was negatively correlated with most emotional problems and problem behaviors. Emotional and attention-related variables were predictors of quality of life. A multidisciplinary approach focusing on the emotional problems of juvenile inmates with ADHD and treatments that improve attention is expected to have a larger effect on their quality of life, in addition to recovery from the disease, recovery of daily function, and social rehabilitation.

\section{Acknowledgments}

This study was supported by a grant of the Korean Mental Health Technology R\&D Project, Ministry of Health \& Welfare, Republic of Korea (HM15C1040).

\section{Conflicts of Interest}

The authors have no potential conflicts of interest to disclose.

\section{Author Contributions}

Conceptualization: Bongseog Kim. Data curation: Bongseog Kim. Formal analysis: Hyesoon Kim. Funding acquisition: Bongseog Kim. Methodology: Bongseog Kim. Project administration: Bongseog Kim. Resources: Bongseog Kim. Supervision: Bongseog Kim. Validation: Hyesoon Kim. Visualization: Hyesoon Kim. Writing_original draft: Hyesoon Kim. Writing—review \& editing: Bongseog Kim.

\section{ORCID iDs}

$\begin{array}{ll}\text { Hyesoon Kim } & \text { https://orcid.org/0000-0002-5075-798X } \\ \text { Bongseog Kim } & \text { https://orcid.org/0000-0002-2534-6986 }\end{array}$

\section{REFERENCES}

1) Choi SH, Park HS. A study on juvenile felony crime. Soeul: Korean Institute of Criminology;2014.

2) Cheung C-K, Ngai N-P, Ngai SS-Y. Family strain and adolescent delinquency in two Chinese cities, Guangzhou and Hong Kong. J Child Fam Stud 2007;16:626-641.

3) Koolhof R, Loeber R, Wei EH, Pardini D, D'Escury AC. Inhibition deficits of serious delinquent boys of low intelligence. Crim Behav Ment Health 2007;17:274-292.

4) Mann EA, Reynolds AJ. Early intervention and juvenile delinquency prevention: evidence from the Chicago Longitudinal Study. Soc Work Res 2006;30:153-167.

5) Abram KM, Teplin LA, McClelland GM, Dulcan MK. Comorbid psychiatric disorders in youth in juvenile detention. Arch Gen Psychiatry 2003;60:1097-1108.

6) Colins O, Vermeiren R, Vreugdenhil C, van den Brink W, Doreleijers T, Broekaert E. Psychiatric disorders in detained male adolescents: a systematic literature review. Can J Psychiatry 2010;55: 255-263.

7) Harzke AJ, Baillargeon J, Baillargeon G, Henry J, Olvera RL, Torrealday $\mathrm{O}$, et al. Prevalence of psychiatric disorders in the Texas Juvenile Correctional System. J Correct Health Care 2012;18:143157.

8) Kim JI, Kim B, Kim BN, Hong SB, Lee DW, Chung JY, et al. Prevalence of psychiatric disorders, comorbidity patterns, and repeat offending among male juvenile detainees in South Korea: a crosssectional study. Child Adolesc Psychiatry Ment Health 2017;11:6.

9) Teplin LA, Abram KM, McClelland GM, Dulcan MK, Mericle AA. Psychiatric disorders in youth in juvenile detention. Arch Gen Psychiatry 2002;59:1133-1143.

10) Ulzen TPM, Psych DC, Hamilton H. The nature and characteristics of psychiatric comorbidity in incarcerated adolescents. Can J Psychiatry 1998;43:57-63.

11) Vreugdenhil C, Doreleijers TA, Vermeiren R, Wouters LF, van den Brink W. Psychiatric disorders in a representative sample of incarcerated boys in the Netherlands. J Am Acad Child Adolesc Psychiatry 2004;43:97-104.

12) Young SJ, Adamou M, Bolea B, Gudjonsson G, Müller U, Pitts M, et al. The identification and management of ADHD offenders within the criminal justice system: a consensus statement from the UK Adult ADHD Network and criminal justice agencies. BMC Psychiatry 2011;11:32.

13) Young S, Gudjonsson GH, Wells J, Asherson P, Theobald D, Oli- 
ver B, et al. Attention deficit hyperactivity disorder and critical incidents in a Scottish prison population. Pers Individ Dif 2009;46: 265-269.

14) Danckaerts M, Sonuga-Barke EJ, Banaschewski T, Buitelaar J, Döpfner M, Hollis C, et al. The quality of life of children with attention deficit/hyperactivity disorder: a systematic review. Eur Child Adolesc Psychiatry 2010;19:83-105.

15) Riley AW, Coghill D, Forrest CB, Lorenzo MJ, Ralston SJ, Spiel G; ADORE Study Group. Validity of the health-related quality of life assessment in the ADORE study: Parent Report Form of the CHIPChild Edition. Eur Child Adolesc Psychiatry 2006;15 Suppl 1:I63I71.

16) Park BE, Lee JS, Kim HY, Bae JN, Kim WH, Kim HY, et al. The influence of depression and school life on the quality of life of Korean child and adolescent patients with attention-deficit/hyperactivity disorder: a comparison of the perspectives of the patients and their caregivers. J Korean Acad Child Adolesc Psychiatry 2019;30: 2-8.

17) Kim YS, Cheon KA, Kim BN, Chang SA, Yoo HJ, Kim JW, et al. The reliability and validity of Kiddie-Schedule for Affective Disorders and Schizophrenia-Present and Lifetime Version-Korean version (K-SADS-PL-K). Yonsei Med J 2004;45:81-89.

18) Sheehan DV, Lecrubier Y, Sheehan KH, Amorim P, Janavs J, Weiller E, et al. The Mini-International Neuropsychiatric Interview (M.I.N.I.): the development and validation of a structured diagnostic psychiatric interview for DSM-IV and ICD-10. J Clin Psychiatry 1998;59 Suppl 20:22-33.

19) Yoo SW, Kim Y, Noh JS, Oh KS, Kin CH, Namkoong K, et al. Validity of Korean version of the Mini-International Neuropsychiatric Interview. Anxiety Mood 2006;2:50-55.

20) Varni JW, Seid M, Kurtin PS. PedsQL ${ }^{\text {TM }} 4.0$ : reliability and validity of the Pediatric Quality of Life Inventory ${ }^{\mathrm{TM}}$ version 4.0 Generic Core Scales in healthy and patient populations. Med Care 2001;
39:800-812.

21) Kook SH, Varni JW. Validation of the Korean version of the Pediatric Quality of Life Inventory ${ }^{\mathrm{TM}} 4.0$ (PedsQL ${ }^{\mathrm{TM}}$ ) Generic Core Scales in school children and adolescents using the Rasch model. Health Qual Life Outcomes 2008;41:1-15.

22) Achenbach TM, Rescorla LA. Manual for the ASEBA school-age forms \& profiles: an integrated system of multi-informant assessment. Burlington, VT: ASEBA;2001.

23) Oh KJ, Kim YA, Ha EH, Lee H, Hong KE. Korean version of youth self report. Seoul: Huno Consulting Inc.;2011.

24) Lee HG, Shin HS, Lee KS. Development of a self-report form of the adolescent problem behavior rating scale: tests of its reliability and validity. Kor J Clin Dev Psychol 2004;17:147-170.

25) Rösler M, Retz W, Retz-Junginger P, Hengesch G, Schneider M, Supprian T, et al. Prevalence of attention deficit-/hyperactivity disorder (ADHD) and comorbid disorders in young male prison inmates. Eur Arch Psychiatry Clin Neurosci 2004;254:365-371.

26) Vermeiren R. Psychopathology and delinquency in adolescents: a descriptive and developmental perspective. Clin Psychol Rev 2003;23:277-318.

27) Wolraich ML, Hannah JN, Pinnock TY, Baumgaertel A, Brown J. Comparison of diagnostic criteria for attention-deficit hyperactivity disorder in a county-wide sample. J Am Acad Child Adolesc Psychiatry 1996;35:319-324.

28) Young S, Morris R, Toone B, Tyson C. Planning ability in adults with attention-deficit/hyperactivity disorder. Neuropsychology 2007;21:581-589.

29) Skirrow C, McLoughlin G, Kuntsi J, Asherson P. Behavioral, neurocognitive and treatment overlap between attention-deficit/hyperactivity disorder and mood instability. Expert Rev Neurother 2009;9:489-503.

30) Young S, Thome J. ADHD and offenders. World J Biol Psychiatry 2011;12 Suppl 1:124-128. 